\title{
Influence of Air Humidity on Transonic Flows with Weak Shock Waves
}

\author{
DYKAS Sławomir*, MAJKUT Mirosław, SMOLKA Krystian
}

Institute of Power Engineering and Turbomachinery, Silesian University of Technology, Konarskiego 18, Gliwice 44-100, Poland

(C) The Author(s) 2019

\begin{abstract}
The paper presents CFD results for the transonic flow of dry and moist air through a diffuser and a compressor rotor. In both test geometries, i.e. the Sajben transonic diffuser and the NASA Rotor 37, the air humidity impact on the structure of flows with weak shock waves was examined. The CFD simulations were performed by means of an in-house CFD code, which was the RANS-based modelling approach to compressible flow solutions. It is shown that at high values of relative humidity, above $70 \%$, the modelling of the transonic flow field with weak shock waves by means of the dry air model may produce wrong results.
\end{abstract}

Keywords: dry air, moist air, transonic flow, weak shock wave, steam condensation

\section{Introduction}

Atmospheric air always contains a certain amount of water or steam. The water content in atmospheric air is usually represented using relative humidity, which is the ratio between the amount of water actually contained in the air and the amount the air can hold. It is expressed in percentages and the relative humidity value for saturated air is $100 \%$. Atmospheric air relative humidity depends on geographical location and current weather. The most humid places on Earth are generally located closer to the equator, near coastal regions. There are a lot of places in the world where average relative humidity is higher than $70 \%$. For instance, in many big cities with a huge transport of air, relative humidity of the day may reach up to $90 \%$ (e.g., Houston in Texas). Therefore, it is natural to check how air humidity can affect the aerodynamics of aircraft elements, especially in the region of transonic air velocities.

In moist air transonic flows above the sonic line, there are suitable conditions for the homogeneous condensation process to arise. In the presence of air impurities, additional phenomena may occur, like heterogeneous condensation, which is investigated in our previous works (e.g. [1]).

In the field of experimental and numerical studies on moist air transonic flows, the most popular ones are the works of Schnerr and his research team [2, 3]. Schnerr proposed a physical model for steam condensing flow modelling, which has been successfully used by many researchers until today.

Elevated relative humidity values affect the characteristic of the wing under the transonic flow conditions [2-5]. They may also have a significant influence on the flow in the turbine engine elements [6].

The moist air transonic flow in the turbine engine can take place in the compressor (or fan) inlet channels or in the compressor (or fan) rotor blade-to-blade channels. In both cases, the transition from subsonic to supersonic conditions (and vice versa) is carried out on weak shock waves. The subject of this paper is to present the influence of air humidity on the performance of the transonic diffuser and the compressor rotor in the presence of weak shock waves.

Received: Feb 26, 2019 AE: GOVARDHAN M. Corresponding author: DYKAS Sławomir E-mail: slawomir.dykas@polsl.p1 www.springerlink.com 


\begin{tabular}{llll}
\hline \multicolumn{2}{l}{ Nomenclature } & & \\
$c$ & absolute velocity $/ \mathrm{m} \cdot \mathrm{s}^{-1}$ & $x, y, z$ & Cartesian coordinates $/ \mathrm{m}$ \\
$c_{p}$ & specific heat at constant pressure $/ \mathrm{J} \cdot \mathrm{kg}^{-1} \cdot \mathrm{K}^{-1}$ & $y$ & adiabatic component \\
$h$ & specific enthalpy $/ \mathrm{J} \cdot \mathrm{kg}^{-1}$ & $\eta$ & adiabatic efficiency \\
$M$ & Mach number & Subscripts & \\
$p$ & static pressure $/ \mathrm{Pa}$ & 0 & total parameter \\
$T$ & temperature $/ \mathrm{K}$ & 1 & inlet \\
$u$ & tangential blade velocity $/ \mathrm{m} \cdot \mathrm{s}^{-1}$ & 2 & outlet \\
$w$ & relative velocity $/ \mathrm{m} \cdot \mathrm{s}^{-1}$ & $\mathrm{~s}$ & isentropic parameter \\
\hline
\end{tabular}

The CFD results presented herein were obtained by means of an in-house CFD code for dry air and they were compared with CFD results of moist air at the air relative humidity value of $70 \%$. As already shown in previous works [7], for relative humidity lower than 70\%, CFD results obtained for moist and dry air do not differ significantly in terms of changes in the flow structure.

\section{Physical and Numerical Model}

The CFD calculations presented herein were made by means of an in-house academic code, which has been developed and used for many years for many engineering applications, including the modelling of moist air flows [8]. The applied computational code was mainly used to identify the condensation phenomenon in the transonic flow.

The presented code solves the RANS equations by means of the third-order MUSCL-type TVD finitevolume scheme with the explicit second-order RungeKutta method for time integration. The finite-volume cell-centred discretization for a multi-block structured mesh was employed. The $k$ - $\omega$ Shear Stress Transport viscous turbulence model [9] was applied. The used model of the compressible, viscous and turbulent flow of moist air is composed of:

- the mass, momentum and energy conservation equations for the air and steam/water mixture;

- the turbulence model equations;

- the transport equations for the liquid phase arising due to homogeneous condensation;

- the relations modelling the condensation process according to the classical theory of nucleation and to the molecular-kinetic droplet growth model [10];

- the ideal gas equation of state.

\section{Transonic Diffuser}

Here, the air flow in a convergent-divergent nozzle is modelled using the in-house CFD code. The case was studied experimentally by Sajben and his team [11]. Usually, two test cases are studied for the Sajben transonic diffuser, corresponding to the strong or weak shock wave, depending on the value of back pressure. For both cases, normal shock waves arise with a transition from supersonic to subsonic conditions on the shock wave, but for a weak shock, the difference between the Mach numbers ahead and behind of the shock is very small. For the weak-shock case, the Mach number ahead the shock was $\sim 1.1$, and behind the shock $\sim 0.9$. According to the basics of aerodynamics, a weak shock usually means an oblique shock wave if supersonic conditions still prevail behind the shock, despite the velocity drop on the shock wave.

In this study, the air flow through a Sajben diffuser was solved for exit pressure corresponding to the weak shock wave of $0.11066 \mathrm{MPa}$. The diffuser inlet total parameters were set to $0.13499 \mathrm{MPa}$ and $277.7 \mathrm{~K}$.

The transonic diffuser geometry and numerical mesh are shown in Fig. 1. The total number of control volumes in the numerical mesh applied for the diffuser is $\sim 9$.

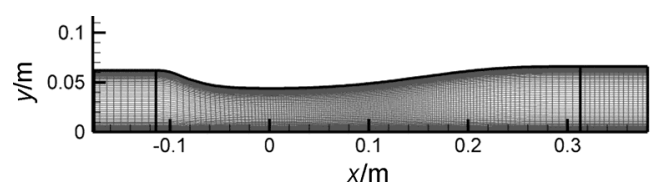

Fig. 1 Numerical mesh applied for the transonic diffuser

\subsection{Dry-air calculations}

The boundary conditions assumed for the transonic diffuser inlet and outlet give the solution of the flow governing equations with the weak shock wave (Fig. 2) formed right downstream the nozzle throat. This position is strongly dependent on correct modelling of the boundary layer and the flow turbulence effects.

Fig. 3 shows static pressure distributions along the diffuser top and bottom walls obtained from CFD calculations and from experiments [11]. The CFD results generally agree with the experimental data; the shock occurs slightly more upstream than in the experiment.

\subsection{Moist-air calculations}

The moist-air calculations were performed assuming relative humidity of $70 \%$. The condensation process 
weakens the shock wave, shifting it downstream, and increases the static temperature in the supersonic region compared to the calculations for dry air (Fig. 4). This can also be observed in the distribution of static pressure on the diffuser walls (Fig. 5), where the CFD results do not agree with experimental data because rapid precipitation of the liquid phase caused a pressure rise in the place of the weak shock.
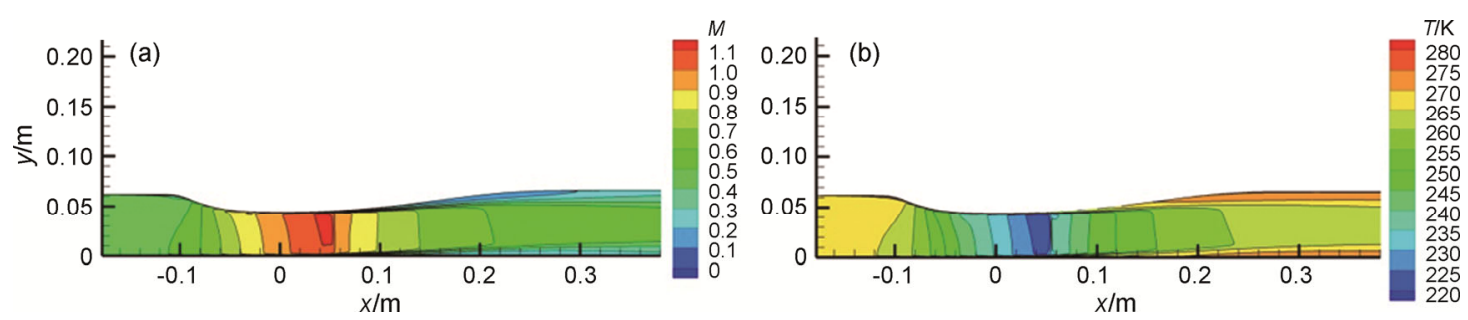

Fig. 2 Mach number (a) and static temperature (b) contours - dry air
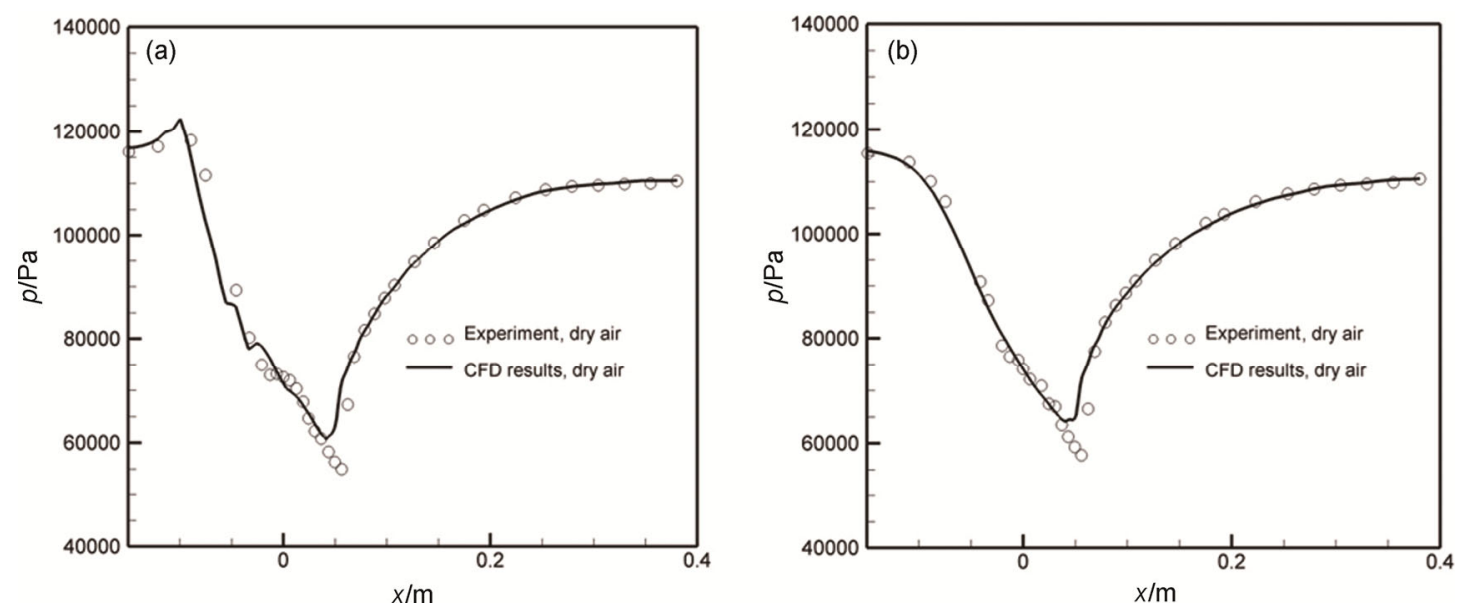

Fig. 3 Static pressure distributions for top (a) and bottom (b) walls - dry air

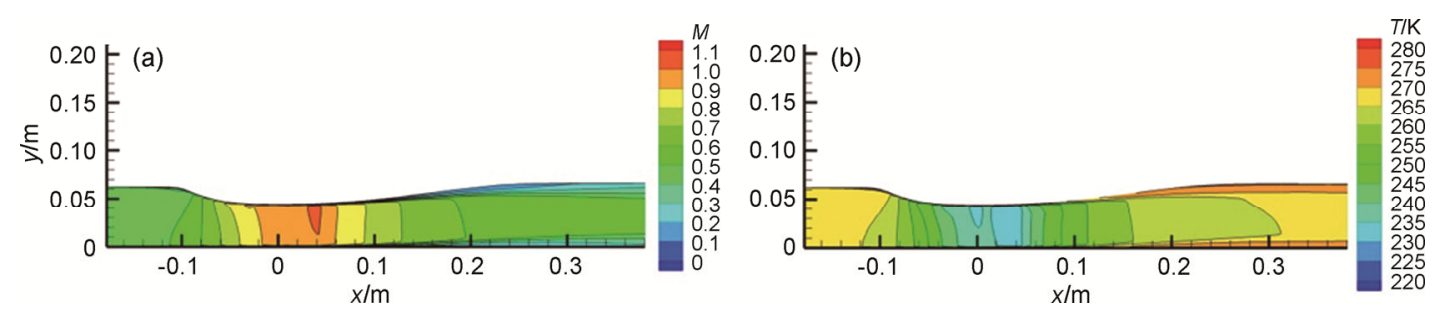

Fig. 4 Mach number (a) and static temperature (b) contours - moist air
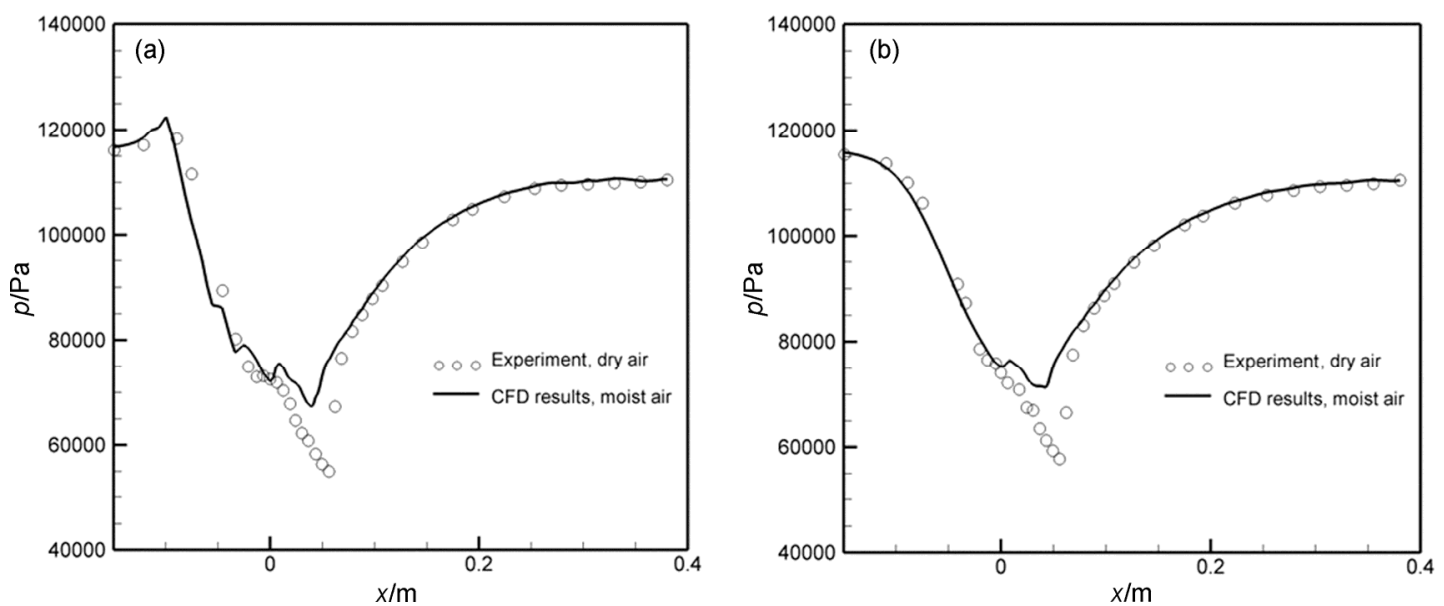

Fig. 5 Static pressure distributions for the top (a) and bottom (b) wall - moist air 
In the vicinity of the end of the diffuser divergent part, a certain amount of the liquid phase formed due to the condensation process evaporates due to a considerable rise in temperature on the shock wave (Fig. 6).

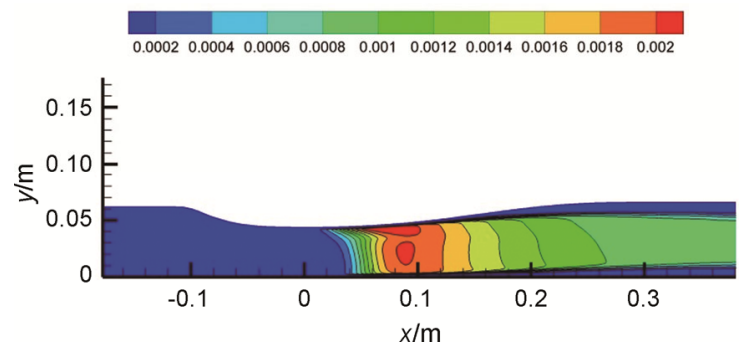

Fig. 6 Wetness mass fraction contours, $\mathrm{kg}_{\text {water }} / \mathrm{kg}_{\text {air }}$

A different situation occurs for the test case with a lower back pressure value at the outlet of $0.097216 \mathrm{MPa}$, corresponding to a stronger shock wave. In this case, the condensation process does not affect the shock wave position.

\section{Transonic Rotor}

The NASA Rotor 37 transonic rotor compressor was used for the next test. The device was designed and tested at the NASA Lewis Research Center [12]. This test case is very popular and it has been analysed by many researchers, for instance, Denton [13], Benini and Biollo [14] or Calvert and Ginder [15].

The assumed CFD modelling boundary conditions correspond to the rotor maximum adiabatic efficiency of $\eta=0.867$ (e.g. [16]). The efficiency was defined for absolute total parameters upstream and downstream the rotor (Fig. 7 and Fig. 8), where enthalpy was replaced with the product of specific heat at constant pressure and temperature.

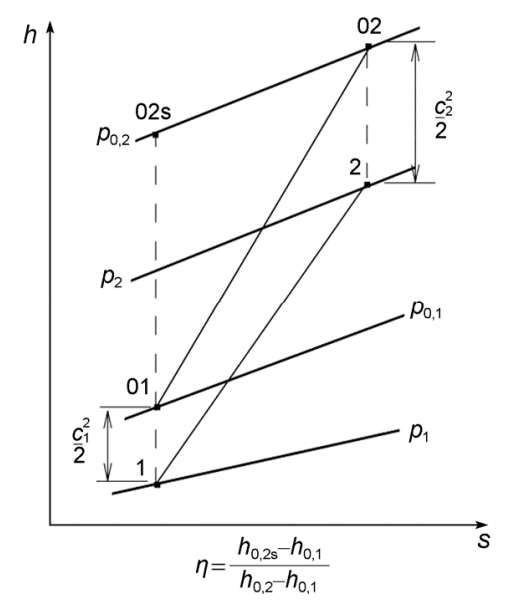

Fig. 7 Heat diagram and efficiency definition
Replacing for the isentropic process the temperature ratio with the pressure ratio, efficiency can be written as follows:

$$
\begin{aligned}
\eta & =\frac{c_{p} T_{0,2 \mathrm{~s}}-c_{p} T_{0,1}}{c_{p} T_{0,2}-c_{p} T_{0,1}}=\frac{T_{0,2 \mathrm{~s}} / T_{0,1}-1}{T_{0,2} / T_{0,1}-1} \\
& =\frac{\left(p_{0,2} / p_{0,1}\right)^{\gamma-1 / \gamma}-1}{T_{0,2} / T_{0,1}-1}
\end{aligned}
$$
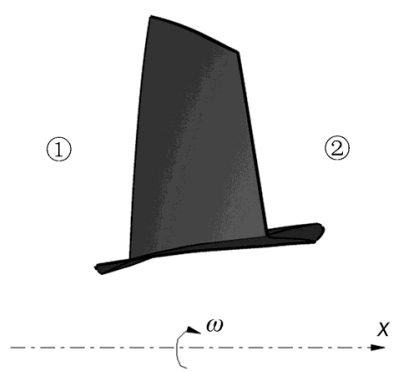

Fig. 8 Compressor rotor geometry

The rotor rotational speed was $17188.7 \mathrm{r} / \mathrm{min}$ (1800 $\mathrm{rad} / \mathrm{s}$ ), leading to a tip-speed in relative frame of $M \sim 1.4$. The rotor-tip gap was not taken into account in the presented calculations; the hub, the blade and the shroud in the computational model were rotating. At the inlet, absolute (in the absolute frame) total pressure and temperature values of $0.1 \mathrm{MPa}$ and $288 \mathrm{~K}$, respectively, were assumed as constant along the blade span. The inlet absolute angle was $0^{\circ}$ (Fig. 9), which means that the axial inlet was assumed. The static outlet pressure at the mean radius was set to $0.1175 \mathrm{MPa}$. At the outlet, the radial equilibrium outlet boundary condition proposed by Arts [17] was implemented in the model.

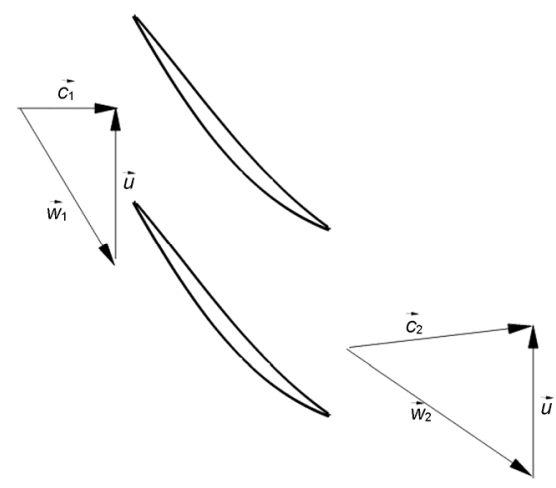

Fig. 9 Velocity triangles for the compressor rotor

The structural multi-grid computational domain containing about 800000 cells (Fig. 10) was prepared using the ICEM CFD software. It was ensured that along the surfaces $y^{+}=1$ to 2 to comply with the SST turbulence model. 

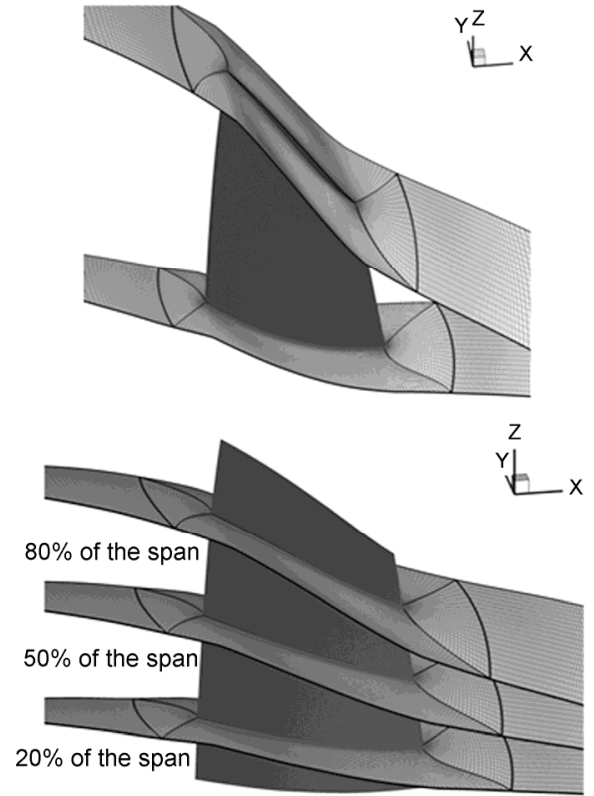

Fig. 10 NASA Rotor 37 computational domain and numerical mesh

\subsection{Dry-air calculations}

At the maximum efficiency boundary conditions, the measured mass flow was $20.74 \mathrm{~kg} / \mathrm{s}$ and the total absolute pressure ratio was 2.077. Fig. 11 shows the radial distribution of the measured $[12,16]$ and the calculated pressure ratio. A significant deviation of the predicted total pressure ratio from experimental data can be seen in the vicinity of the blade tip, which may be due to the fact that the tip rotor gap was not included in the CFD model. The mean total pressure ratio from the CFD calculations totalled 2.065 and the mass flow was 0.556 $\mathrm{kg} / \mathrm{s}$ for a single blade-to-blade channel. Multiplied by 36 channels, this gives the total mass flow value of 20.01 $\mathrm{kg} / \mathrm{s}$. The rotor calculated adiabatic efficiency was 0.846 , which is about 2 percentage points less than that in the experiment.

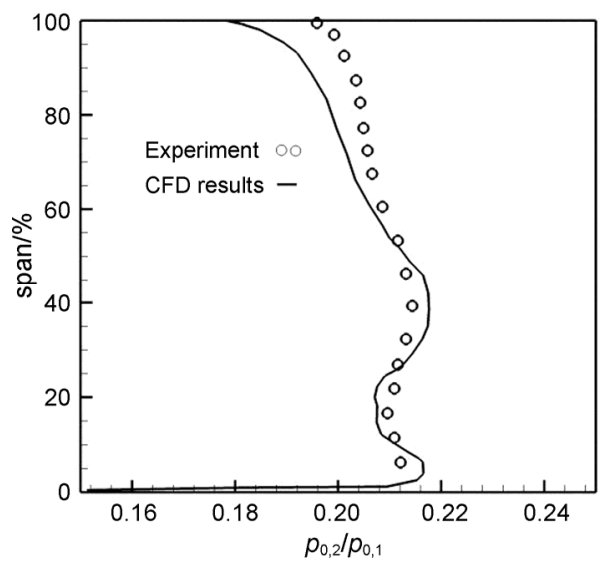

Fig. 11 Comparison of total pressure ratio profiles from the experiment and the CFD calculations
Fig. 12, Fig. 13 and Fig. 14 present the static temperature and the relative Mach number (calculated on the basis of relative velocity) contours at $20 \%, 50 \%$ and $80 \%$ of the blade span (i.e. close to the hub, in the middle, and close to the shroud). For supersonic flows into the rotor blade row in the relative coordinate system, a weak bow shock wave is formed upstream the blade leading edge, which interacts with the blade suction side.
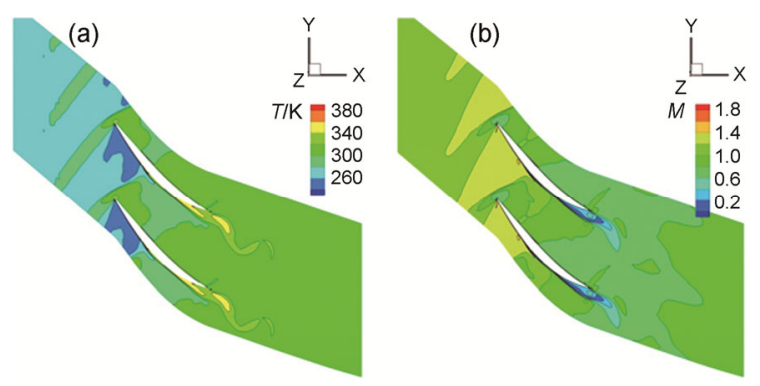

Fig. 12 Static temperature (a) and relative Mach numbers (b) contours $-20 \%$ of the blade span
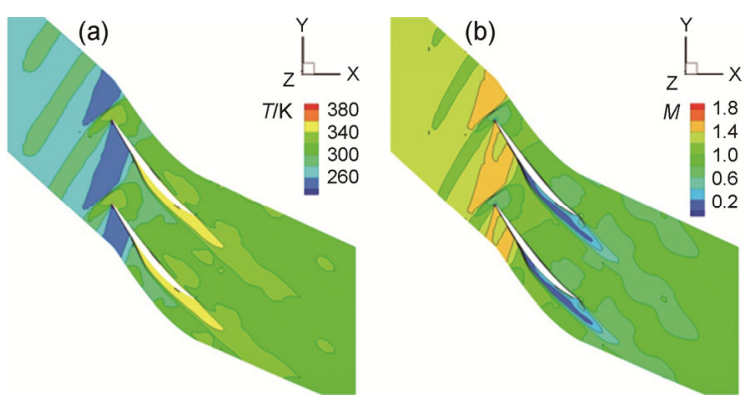

Fig. 13 Static temperature (a) and relative Mach numbers (b) contours $-50 \%$ of the blade span
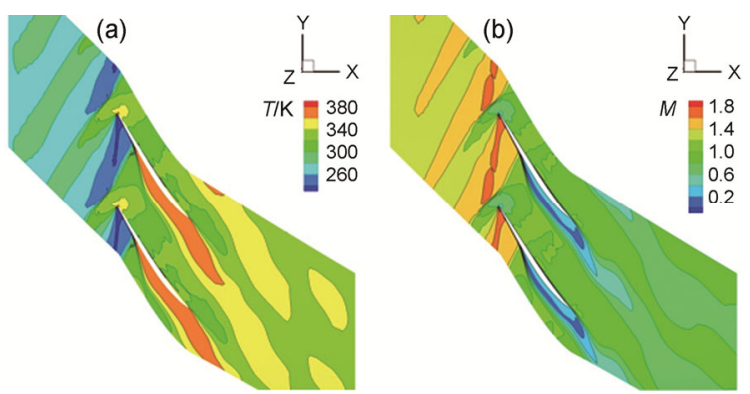

Fig. 14 Static temperature (a) and relative Mach numbers (b) contours $-80 \%$ of the blade span

\subsection{Moist-air calculations}

The moist-air CFD calculations were performed for the same boundary conditions as for dry air, but relative humidity of $70 \%$ was assumed at the inlet. The wetness mass fraction created due to homogeneous condensation of steam is present only on the blade suction side in the 
vicinity of the leading edge (Fig. 16). However, most of the liquid phase occurs in $60 \%$ to $95 \%$ of the rotor blade span. This is the area where the largest changes in the flow structure are observed (Fig. 17).

The high amount of the liquid phase in the tip region of the rotor blade involves changes in the flow structure, compared to the dry air flow, both in the static temperature and the relative Mach number contours (Fig. 17) and in the static pressure distribution on the blade surface (Fig. 15).

The liquid phase formed due to homogeneous condensation evaporates on the shock wave, decreasing the temperature right behind it (Fig. 18), and deflects downstream the bow shock interacting with the blade suction side close to the leading edge. However, the temperature at the rotor outlet at the tip is higher for the moist air flow mainly due to the change in the flow structure and enlargement of the flow-separation region behind the blade. Finally, it causes a reduction in

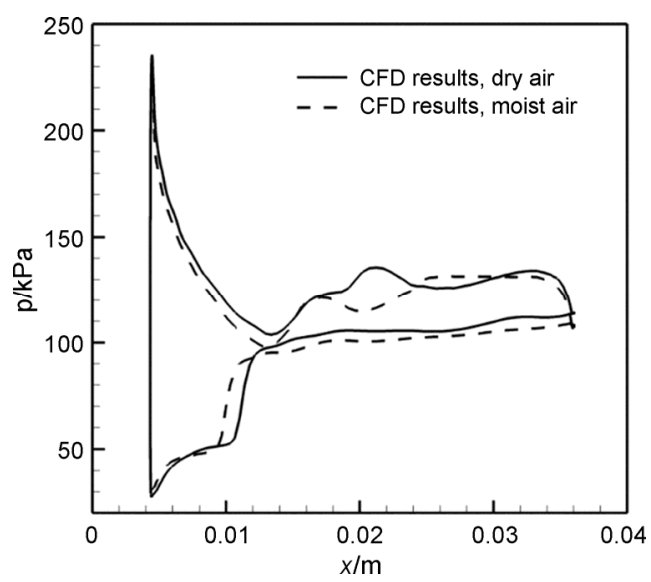

Fig. 15 Static pressure distributions on the blade surface $80 \%$ of the blade span

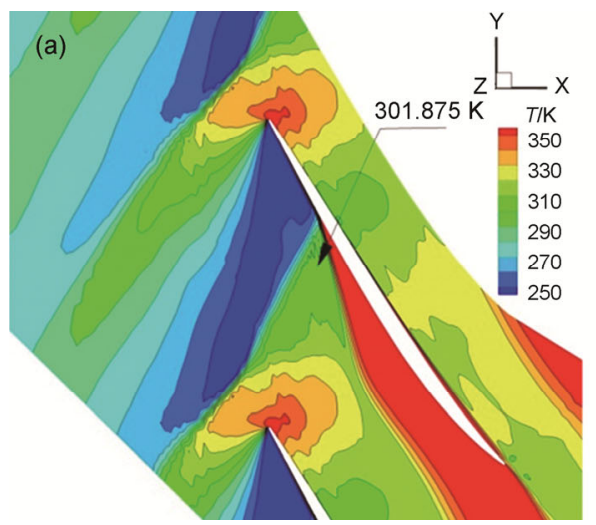

efficiency in the rotor tip region. As a result, the moist air flow overall efficiency is about 4 percentage points lower compared to the dry air flow calculations.

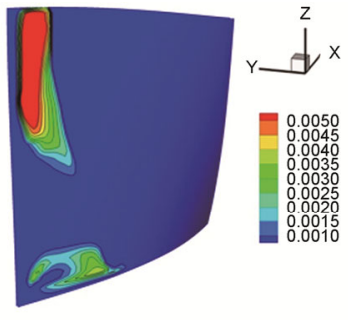

Blade suction side,

$1 \mathrm{~mm}$ from the wall

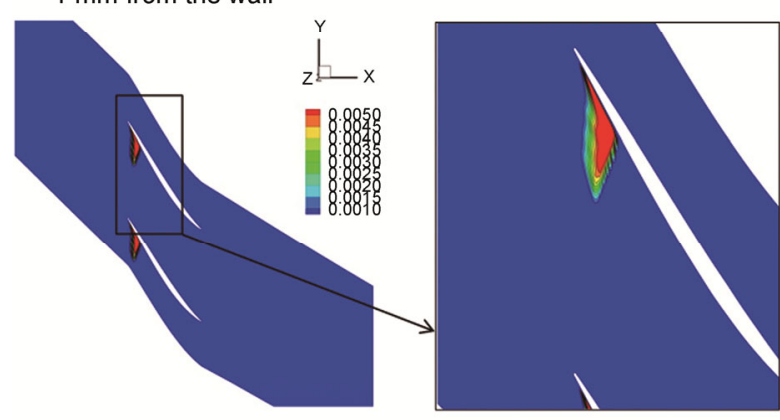

At $80 \%$ of blade span

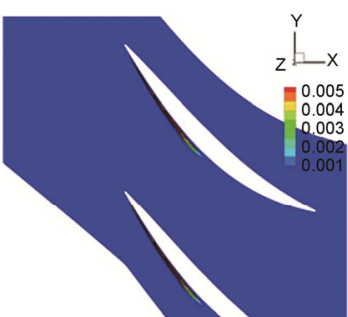

At $5 \%$ of blade span
Fig. 16 Wetness fraction contours, $\mathrm{kg}_{\mathrm{water}} / \mathrm{kg}_{\mathrm{air}}$

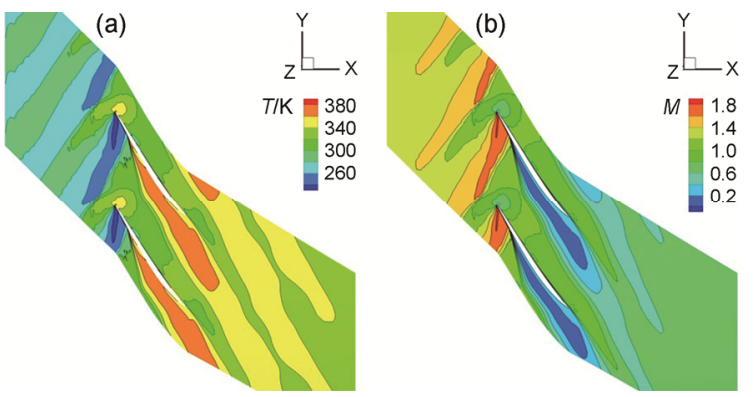

Fig. 17 Static temperature (a) and relative Mach number (b) contours $-80 \%$ of the blade span

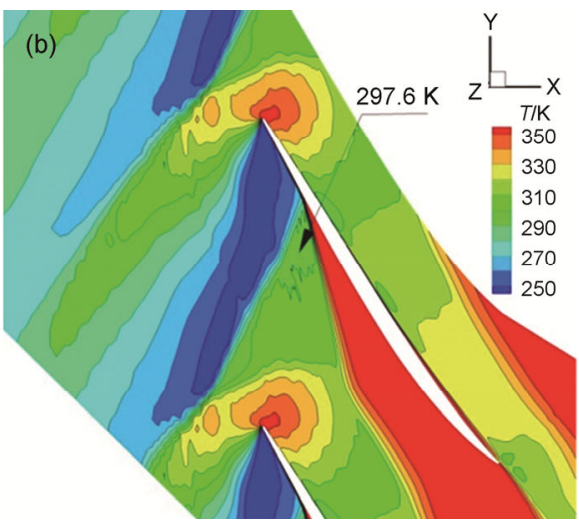

Fig. 18 Contours of static temperature for dry air (a) and moist air (b) $-80 \%$ of the blade span 


\section{Conclusions}

The present work refers to the CFD numerical simulations of the transonic flows of dry and moist air. Current validation against experimental data proved the applied CFD code capacity for modelling transonic flows of dry air. Also, discussed in this paper, comparisons of the CFD results with experimental data for both dry air test cases confirm the accuracy and robustness of the applied in-house CFD code for the transonic flows with weak shock waves. In our previous experimental and CFD study $[1,7]$ of the moist air transonic flows, a significant change of the flow field structure with the rise of the atmospheric air relative humidity was shown. However, for the flows with strong shock waves, especially back pressure shock wave [7], the value of the relative humidity mostly does not affect significantly the position and strength of the shock waves. Whereas for the weak shock waves, e.g. for oblique or bow shock waves appearing in the blade to blade compressor channels, the high value, above $70 \%$, of the air relative humidity changes the flow field structure.

Comparing the presented herein calculation results for the transonic diffuser and axial compressor rotor for dry and moist air at the relative humidity value of $70 \%$, significant changes in the flow field structure can be observed in the vicinity of the weak shock waves. In conclusion, in the case of transonic air flows with humidity exceeding $70 \%$, it seems that the crucial issue is to take account of the steam condensation process in the analysis of the flow phenomena arising in the aircraft components, both in external and internal (e.g. in the turbine engine) flows.

\section{Acknowledgements}

The presented work was supported by Statutory Research Funds of the Silesian University of Technology.

\section{References}

[1] Dykas S., Majkut M., Smołka K., Strozik M., Numerical analysis of the impact of pollutants on water vapour condensation in atmospheric air transonic flows. Applied Mathematics and Computation, 2018, 338: 451-465.

[2] Schnerr G.H., Mundinger G., Similarity, drag, and lift in transonic flow with given internal heat addition. European Journal of Mechanics - B/Fluids, 1993, 12(5): 597-611.

[3] Schnerr G.H., Dohrmann U., Transonic flow around airfoils with relaxation and energy supply by homogeneous condensation. AIAA Journal, 1990, 28 : 1187-1193.

[4] Yamamoto S., Hagari H., Murayama M., Numerical simulation of condensation around the 3-D Wing. Transactions of the Japan Society for Aeronautical and Space Sciences, 2000, 42(138): 182-189.

[5] Matsuo S., Yokoo K., Nagao J., Nishiyama Y., Setoguchi T., Dong Kim H., Yu S., Numerical study on transonic flow with local occurrence of non-equilibrium condensation. Open Journal of Fluid Dynamics, 2013, 3: 42-47.

[6] Yamamoto S., Moriguchi S., Miyazawa H., Furusawa T., Effect of inlet wetness on transonic wet-steam and moist-air flows in turbomachinery. International Journal of Heat and Mass Transfer, 2018, 119: 720-732.

[7] Dykas S., Majkut M., Smołka K., Strozik M., Comprehensive investigations into thermal and flow phenomena occurring in the atmospheric air two-phase flow through nozzles. International Journal of Heat and Mass Transfer, 2017, 114: 1072-1085.

[8] Doerffer P., Dykas S., Numerical analysis of shock induced separation delay by air humidity. Journal of Thermal Science, 2005, 14(2): 120-125.

[9] Menter F.R., Two-equation eddy-viscosity turbulence models for engineering applications. AIAA Journal, 1994, 32(8): 1598-1605.

[10] Frenkel J., Kinetic theory of liquids. Dover, New York, 1955.

[11] Bogar T.J., Sajben M., Kroutil J.C., Characteristic frequencies of transonic diffuser flow oscillations. AIAA Journal, 1983, 21(9): 1232-1240.

[12] Reid L., Moore R., Design and overall performance of four highly loaded high-speed inlet stages for an advanced high-pressure ratio core compressor. NASA TP 1338, 1978.

[13] Denton J.D., Lessons from rotor 37. Journal of Thermal Science, 1997, 6(1): 1-13.

[14] Benini E., Biollo R., Aerodynamics of swept and leaned transonic compressor-rotors. Applied Energy, 2007, 84(10): 1012-1027.

[15] Calvert W.J., Ginder R.B., Transonic fan and compressor design. Proceedings of the Institution of Mechanical Engineers Part C: Journal of Mechanical Engineering Science, 1999, 213(5): 419-436.

[16] Dunham J., CFD validation for propulsion system components. Technical Report AR-355, AGARD, 1998.

[17] Arts T., Calculation of the three-dimensional, steady, inviscid flow in a transonic axial turbine stage. Transactions of ASME, Journal of Engineering for Gas Turbines and Power, 1985, 107: 286-292. 